\title{
ANALISA FAKTOR-FAKTOR YANG TURUT MEMPENGARUHI PERILAKU NASABAH DALAM MENGGUNAKAN KARTU DEBIT
}

\author{
Shinta Wahyu Hati \\ STIE Indonesia Malang \\ Jl. Megamendung No. 9 Malang \\ Telp. (0341) 568116 Fax. (0341) 563841 Email: stiei@telkom.net
}

\begin{abstract}
In financial service business banking is help people to make manage their properties, especially money, this is support by healthy and prudential banking to growing people's trust. This research has purposed to find to what kind of factors impacts customers use debt card, it's a shopping style as an alternative payment another credit card. But there are factors impacts customers use debt card are personal factors including of income and education, reference factors including of family and friends advices (social), psychology factors including advertising, and prize, technology factors including faster transaction, more safety, and on line facilities, and dominant factors to affect customers use debt card those factors are the hypothesis in this research.

This field research put 65 bank customer use debt card with purposive sampling, this research use Structural Equation Modelling analysis and the result of this analysis there are two factors to attentioned by customer use debt card are personal factors and psychology factors as the dominant decision factors make customers to use debt card.
\end{abstract}

Key words: bank, debit card, consumer behavior.

Kondisi dunia perbankan di Indonesia telah mengalami banyak perubahan. Perubahan ini dipengaruhi oleh perkembangan internal dunia perbankan dan perkembangan eksternal dunia perbankan. Perkembangan internal perbankan itu diantaranya dengan adanya deregulasi perbankan yang mulai dikeluarkan 1 Juni 1983 (Pakjun 83). Deregulasi yang paling besar dampaknya adalah deregulasi 27 Oktober 1988 (Pakto 88). Dengan bergulirnya deregulasi ini maka pendirian bank swasta menjadi lebih mudah, karena itu banyak muncul bank-bank swasta baru di Indonesia.

Adanya peraturan yang jelas tentang kesehatan perbankan dan rahasia bank menyebabkan peningkatan kepercayaan masyarakat terhadap pihak perbankan. Perkembangan perbankan yang pesat itu akhirnya mengalami kemunduran sejak krisis ekonomi yang melanda Indonesia di pertengahan tahun 1997. Krisis ekonomi ini berdampak sangat besar terhadap tingkat kepercayaan 
masyarakat. Masyarakat menjadi tidak percaya terhadap pihak perbankan, disebabkan banyak masalah yang menimpa dunia perbankan. Karena itu dunia perbankan di Indonesia makin kompetitif. Untuk itu pihak perbankan harus bisa menyesuaikan diri terhadap perubahan yang terjadi. Untuk bisa menarik nasabah sebanyak-banyaknya, pihak bank harus mampu bersaing diantaranya dengan menciptakan produk dan jasa yang sesuai dengan kebutuhan nasabah produk perbankan yang meluas pemakaiannya saat ini adalah kartu debit. Kartu debit ini merupakan kartu yang dikeluarkan oleh bank, untuk membayar transaksi nasabah dengan merchant yang telah bekerja sama dengan bank yang bersangkutan.

Pada dasarnya kartu debit ini seperti membayar tunai tetapi tidak dengan uang tunai, akan tetapi langsung mendebet (mengurangi) rekening nasabah dan mengkredit (menambah) rekening merchant. Pemakaian kartu debit ini makin meluas di Indonesia. Banyak bank yang telah mengeluarkan fasilitas ini. Bagi pihak bank sangat penting untuk mengetahui faktor-faktor apa saja yang dipertimbangkan nasabah dalam menggunakan kartu debit.

\section{BANK}

Definisi lain dari bank menurut UU No.14 Tahun 1967 Pasal 1 tentang Pokok-Pokok Perbankan adalah lembaga keuangan yang usaha pokoknya memberikan kredit dan jasa-jasa dalam lalu-lintas pembayaran dan peredaran uang. Sedangkan A. Abdurrahman dalam Ensiklopedia Ekonomi Keuangan Dan Perdagangan menjelaskan bahwa:

Bank adalah suatu jenis lembaga keuangan yang melaksanakan berbagai macam jasa, seperti memberikan pinjaman, mengedarkan mata uang, pengawasan terhadap mata uang, bertindak sebagai tempat penyimpanan benda-benda berharga, membiayai usaha perusahaanperusahaan dan lain-lain" (Lukman, 2001).

\section{Fungsi Pokok Bank Umum}

Bank umum sebagai lembaga perantara keuangan memberikan jasa-jasa keuangan baik kepada unit surplus maupun kepada unit defisit. Bank umum mempunyai fungsi pokok sebagaimana yang tercantum menurut Dahlan Siamat (1995), adalah sebagai berikut: 
a) Menyediakan mekanisme dan alat pembayaran yang lebih efisien dalam kegiatan ekonomi

b) Menciptakan uang melalui penyaluran kredit investasi

c) Menghimpun dana dan menyalurkannya kepada masyarakat

d) Menyediakan jasa-jasa pengelolaan dana dan trust atau perwalian amanat kepada individu dan perusahaan

e) Menyediakan fasilitas untuk perdagangan internasional

f) Memberikan pelayanan penyimpanan untuk barang-barang berharga

g) Menawarkan jasa-jasa keuangan lain misalnya, credit card, traveler's check, transfer dana dan sebagainya

\section{Penggolongan Kartu Plastik}

a) Credit Card

Kartu kredit atau credit card adalah jenis kartu yang dapat digunakan sebagai alat pembayaran transaksi jual beli barang atau jasa di mana pelunasannya atau pembayarannya kembali dapat dilakukan dengan sekaligus atau dengan cara mencicil sejumlah minimum tertentu.

\section{b) Charge Card}

Charge card adalah kartu yang dapat digunakan sebagai alat pembayaran suatu transaksi jual beli barang atau jasa di mana nasabah harus membayar kembali seluruh tagihan secara penuh pada akhir bulan berikutnya dengan atau tanpa beban biaya tambahan.

\section{c) Debit Card}

Debit card sangat berbeda dengan kedua kartu plastik yang telah disebutkan diatas. Pembayaran atas transaksi jual-beli barang atau jasa dengan menggunakan kartu debit ini pada prinsipnya merupakan transaksi tunai tanpa mengggunakan uang tunai akan tetapi pelunasannya atau pembayarannya dilakukan dengan cara mendebet (mengurangi) secara langsung saldo rekening simpanan pemegang kartu yang bersangkutan dan dalam waktu yang sama mengkredit rekening penjual (merchant) sebesar jumlah nilai transaksi pada bank penerbit (pengelola).

d) Cash Card

Cash card pada dasarnya adalah kartu yang memungkinkan pemegang/pemilik kartu untuk memperoleh/menarik uang tunai baik langsung pada kasir bank maupun melalui ATM bank tertentu yang biasanya tersebar di tempat-tempat strategis. 


\section{Model Perilaku Nasabah}

Perilaku nasabah melibatkan pertukaran diantara individu. Pada kenyataannya peran pemasaran adalah untuk menciptakan pertukaran dengan nasabah melalui formulasi dan penerapan strategi pemasaran. Pemahaman terhadap nasabah dapat dilakukan melalui rangsangan (stimulus). Rangsangan pemasaran dan lingkungan masuk kedalam kesadaran nasabah. Karakteristik nasabah dan proses keputusan membeli menghasilkan keputusan pembelian tertentu. Tugas manager adalah memahami apa yang terjadi dalam kesadaran nasabah antara datangnya stimulasi luar dan keputusan pembelian.

Gambar 1

Model Perilaku Nasabah

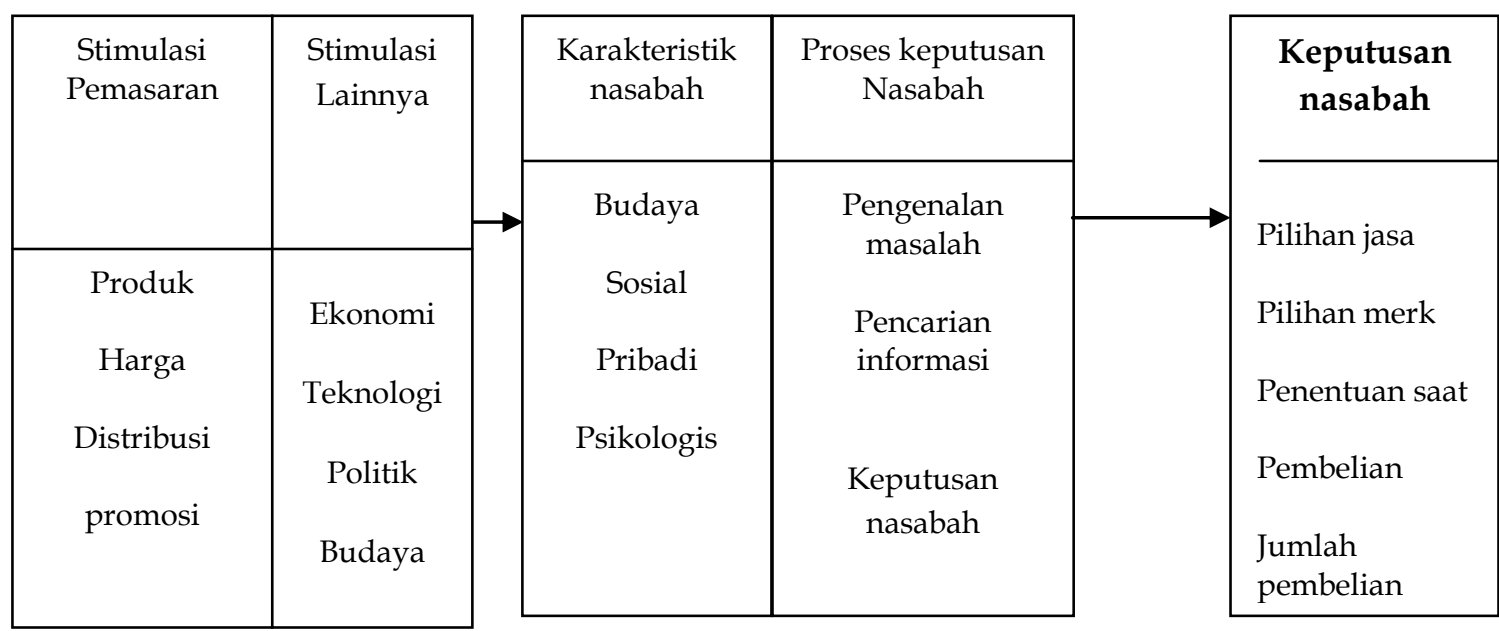

Sumber: Sumarni (2002) Diadosi dari Kotler P (1994) Marketing Management, An Asian Perspective, Prentice Hall, New York.

\section{Model Konsepsi}

Kerangka berfikir yang diajukan penulis sehubungan dengan permasalahan yang diteliti adalah sebagai berikut:

Gambar 2

Model Konsepsi

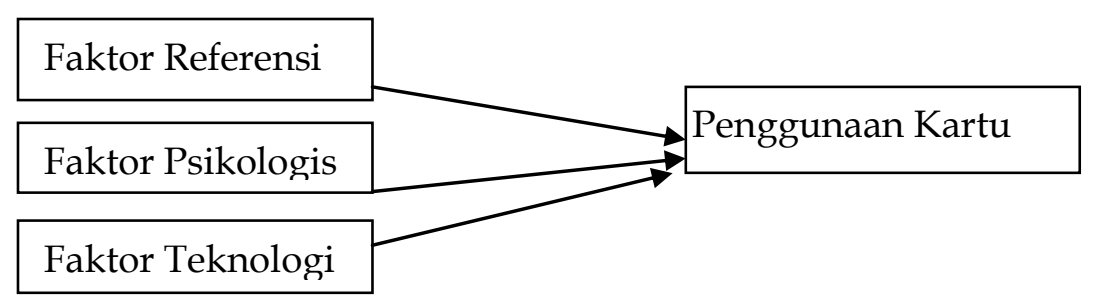


Dari konsepsi diatas agar terjadi pola hubungan dari variabel penelitian dapat diamati dan diukur, maka model konsepsi tersebut dikembangkan dengan model hipotesis sebagai berikut:

Gambar 3

Model Hipotesis

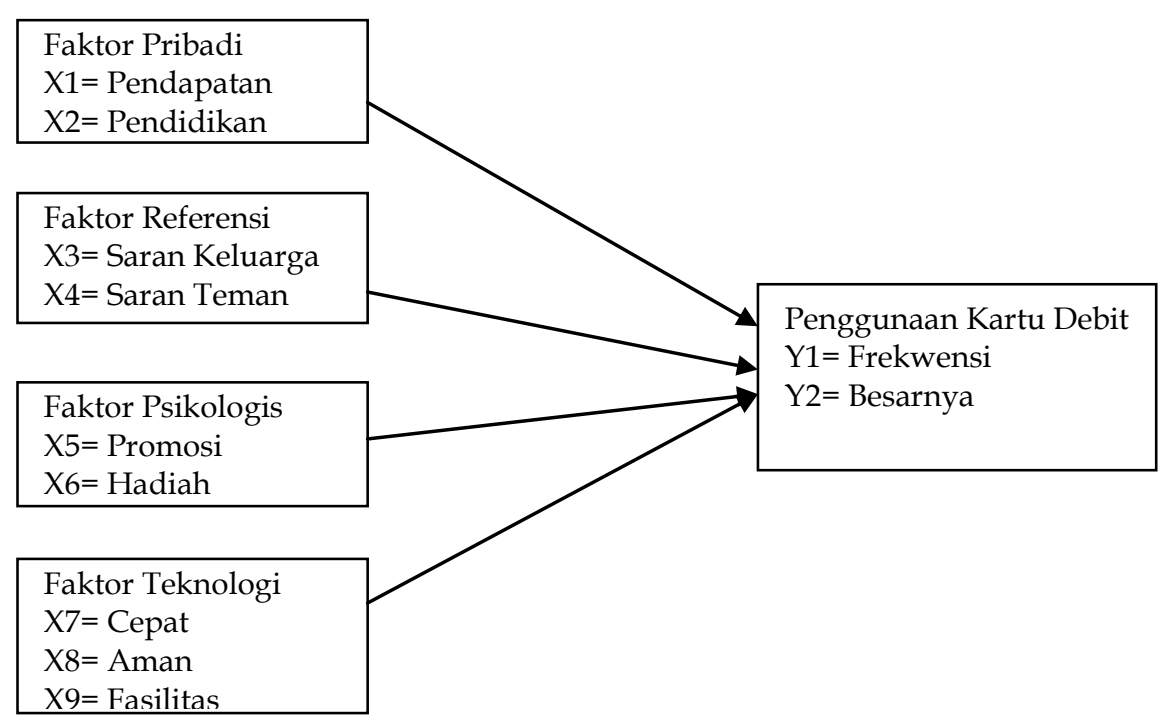

\section{Hipotesis}

Hipotesa yang diajukan oleh peneliti adalah:

1. Diduga faktor pribadi yang terdiri dari pendapatan dan pendidikan merupakan faktor yang turut mempengaruhi perilaku nasabah dalam menggunakan kartu debit.

2. Diduga faktor referensi yang terdiri dari saran keluarga dan saran teman merupakan faktor yang turut mempengaruhi perilaku nasabah dalam menggunakan kartu debit

3. Diduga faktor psikologis yang terdiri dari promosi dan hadiah merupakan faktor yang turut mempengaruhi perilaku nasabah dalam menggunakan kartu debit

4. Diduga faktor teknologi yang terdiri dari transaksi lebih cepat, transaksi lebih aman dan fasilitas on line merupakan faktor yang turut mempengaruhi perilaku nasabah dalam menggunakan kartu debit

5. Diduga terdapat faktor yang dominan pengaruhnya terhadap nasabah dalam menggunakan kartu debit. 


\section{METODE}

Jenis penelitian yang dilakukan pada penelitian ini adalah penelitian field research atau penelitian lapangan, yaitu dengan cara mengumpulkan data dari responden melalui kuesioner. Ruang lingkup penelitian ini adalah bidang pemasaran khususnya mengenai faktor-faktor yang mempengaruhi perilaku nasabah dalam menggunakan kartu debit. Responden yang diambil dalam penelitian ini adala 65 orang. Adapun lokasi pengambilan sampel dilakukan di Ramayana Alun-Alun Mall, Malang. Sedangkan teknik sampling yang digunakan dalam pengambilan sampel adalah purposive sampling, yaitu dengan memilih sebagian nasabah bank yang menggunakan kartu debit sebagai sampel.

\section{Variabel yang Diamati}

Peneliti menggunakan 2 variabel, yaitu:

(a) Variabel bebas (independen variable)

Varibel bebas ini terdiri atas:

1. Faktor pribadi, indikatornya:

$$
\begin{aligned}
& X 1=\text { Pendapatan } \\
& X 2=\text { Pendidikan }
\end{aligned}
$$

2. Faktor referensi, indikatornya:

$$
\begin{aligned}
& \mathrm{X} 3=\text { Saran keluarga } \\
& \mathrm{X} 4=\text { Saran teman }
\end{aligned}
$$

3. Faktor psikologis, indikatornya:

$$
\begin{aligned}
& X 5=\text { Promosi } \\
& X 6=\text { Hadiah }
\end{aligned}
$$

4. Faktor teknologi, indikatornya:

$\mathrm{X} 7$ = Transaksi lebih cepat

$\mathrm{X} 8=$ Transaksi lebih aman

X9 = Fasilitas online

(b) Variabel tergantung (dependen variable)

Variabel tergantung ini hanya ada 1, yaitu penggunaan kartu debit, indikatornya:

1. $\mathrm{Y} 1=$ Frekwensi pemakaian kartu debit

2. $\mathrm{Y} 2=$ Besarnya transaksi 


\section{Model Analisa}

Pada penelitian ini peneliti menganalisa data dengan menggunakan analisa Structural Equation Modelling (SEM) atau juga disebut Linier Structural Equation (LISREL). Adapun langkah-langkah yang ditempuh dalam SEM adalah:

1. Pengembangan model berbasis konsep dan teori

2. Mengkonstruksi diagram path

3. Konversi diagram path ke dalam model struktural

4. Memilih matriks input

5. Menilai masalah identifikasi

6. Evaluasi goodness of fit

7. Interpretasi dan modifikasi model

Penelitian ini bertujuan untuk mengetahui faktor-faktor apa saja yang mempengaruhi perilaku nasabah dalam menggunakan kartu debit. Penelitian ini meliputi 4 variabel laten exogen yaitu faktor pribadi, faktor referesi, faktor psikologis, faktor teknologi, dan 1 variabel laten endogen yaitu penggunaan kartu debit. Adapun variabel manifest (indikator) terdiri dari 11 variabel, yaitu:

$\begin{array}{lllll}\text { X1 } & =\text { Pendapatan } & \text { X7 } & = & \text { Cepat } \\ \text { X2 } & =\text { Pendidikan } & \text { X8 } & = & \text { Aman } \\ \text { X3 } & =\text { Saran keluarga } & \text { X9 } & = & \text { Fasilitas } \\ \text { X4 } & =\text { Saran teman } & \text { Y1 } & = & \text { Frekwensi } \\ \text { X5 } & =\text { Promosi } & \text { Y2 } & = & \text { Besarnya transaksi } \\ \text { X6 } & =\text { Hadiah } & & \end{array}$

\section{Pengembangan Model Berbasis Konsep dan Teori}

Berikut landasan teori berkaitan dengan perilaku konsumen, diambil dari Kotler (1996:153), bahwa faktor utama yang mempengaruhi perilaku pembelian adalah faktor referensi, kelompok refensi termasuk dalam faktor sosial. Faktor pribadi juga termasuk faktor utama yang mempengaruhi perilaku pembelian, pedapatan dan pendidikan termasuk faktor pribadi. Faktor psikologis merupakan faktor utama yang mempengaruhi perilaku pembelian. Menurut Sumarni (2002:77) bahwa setiap perubahan teknologi akan mempengaruhi dunia perbankan. 


\section{Mengkonstruksi Diagram Path}

Berdasarkan landasan teori diatas, seperti pada gambar 3.

\section{Konversi Diagram Path kedalam Model Struktural}

Konversi diagram path kedalam model matematika menjadi sebagai berikut:

$$
\begin{aligned}
& X_{1}=\lambda_{1 .} \xi_{1}+\delta_{1} \quad X_{6}=\lambda_{6} \xi_{3}+\delta_{6} \\
& \mathrm{Y}_{2}=\lambda_{11} \cdot \eta_{2}+\varepsilon_{2} \\
& X_{2}=\lambda_{2 .} \xi_{1}+\delta_{2} \quad X_{7}=\lambda_{7} \xi_{4}+\delta_{7} \\
& X_{3}=\begin{array}{lll}
\lambda_{3} \xi_{2}+\delta_{3} & X_{8}=\lambda_{8} \xi_{4}+\delta_{8}
\end{array} \\
& \mathrm{X}_{4}=\lambda_{4 .} \xi_{2}+\delta_{4} \quad \mathrm{X}_{9}=\lambda_{89} \xi_{4}+\delta_{8} \\
& X_{5}=\lambda_{5} \xi_{3}+\delta_{5} \quad Y_{1}=\lambda_{10} \cdot \eta_{1}+\varepsilon_{1}
\end{aligned}
$$

\section{Gambar 4}

Pembentukan Diagram Path

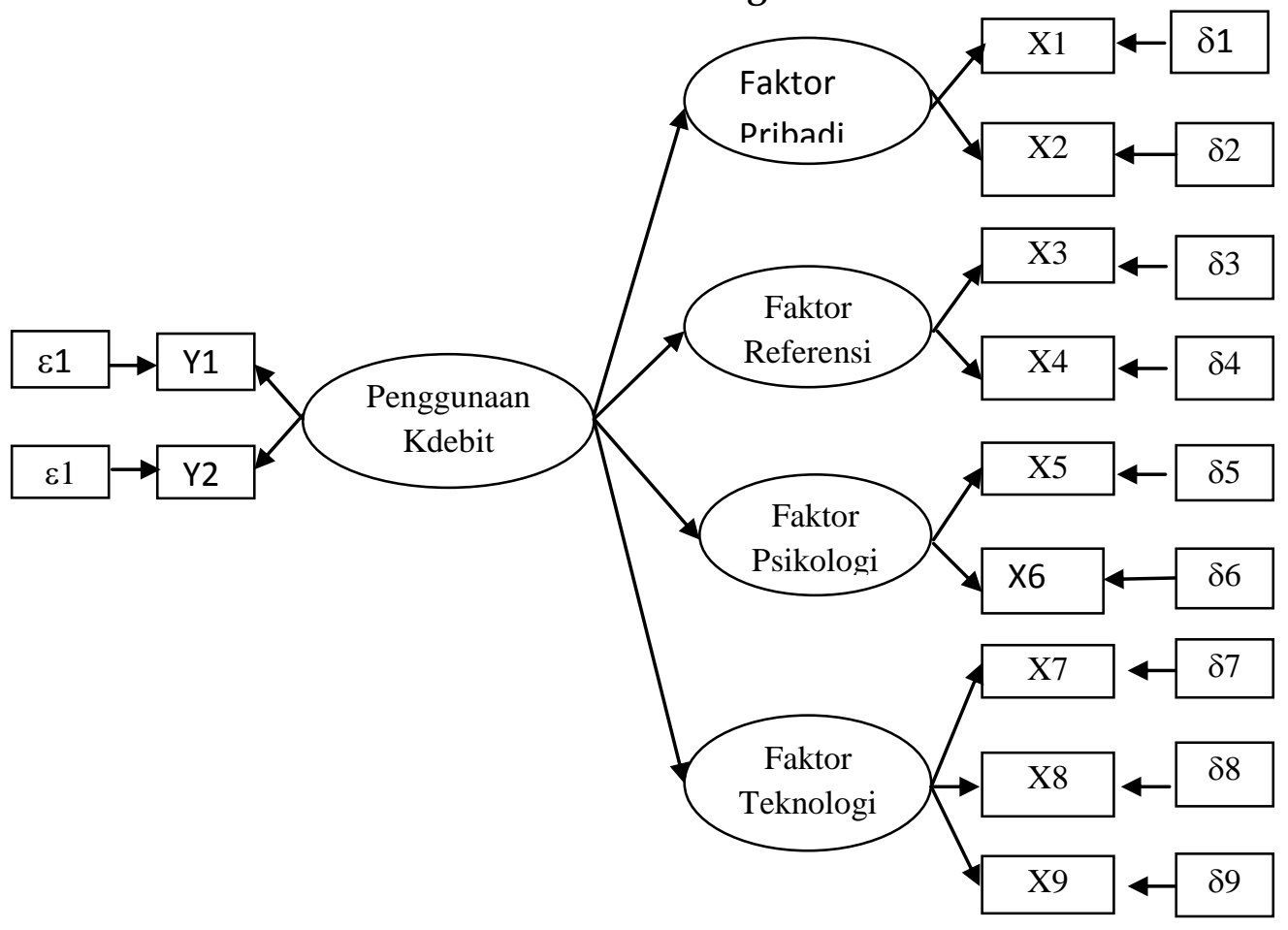

\section{Memilih Matriks Input}

Langkah dalam pemasukan input meliputi 65 sampel yang terdiri dari 11 variabel manifest (indikator). Data input yang dimasukkan berupa matriks korelasi. Dengan matriks korelasi maka dapat diketahui variabel mana yang dominan pengaruhnya dalam mempengaruhi nasabah dalam menggunakan kartu debit. 


\section{Menilai Masalah Identifikasi}

Model ini telah menghasilkan identifikasi yang eksak, sehingga program komputer dapat memproses analisanya Untuk itu tidak perlu memberikan kendala pada model atau memodifikasi ulang model yang digunakan.

\section{HASIL DAN PEMBAHASAN}

\section{Hasil}

\section{a. Evaluasi Goodness-of-Fit}

Uji goodness-of-Fit dapat dilakukan sebagai berikut:

jika nilai t-hitung $>$ t-tabel maka indikator (variabel manifest) tersebut valid sebagai pengukur dari variabel latennya. Tabel berikut akan membandingkan thitung dengan t-tabel.

Tabel 1

Uji-T Parameter Lambda $Y$

\begin{tabular}{|c|c|c|c|}
\hline Indikator Kdebit & T-hitung & T-tabel & Keterangan \\
\hline Y1 & 6,61 & 1,9984 & Valid \\
\hline Y2 & 7,68 & 1,9984 & Valid \\
\hline
\end{tabular}

Tabel 2

Pengujian Parameter Lambda $X$

\begin{tabular}{|c|c|c|c|c|c|}
\hline Indikator & Pribadi & Referensi & Psikologis & Teknologi & Keterangan \\
\hline X1 & 5,77 & -- & -- & -- & Valid \\
\hline X2 & 3,71 & -- & -- & -- & Valid \\
\hline X3 & -- & 5,47 & -- & -- & Valid \\
\hline X4 & -- & 4,01 & -- & -- & Valid \\
\hline X5 & -- & -- & 3,81 & -- & Valid \\
\hline X6 & -- & -- & 2,46 & -- & Valid \\
\hline X7 & -- & -- & -- & 8,62 & Valid \\
\hline X8 & -- & -- & -- & 9,50 & Valid \\
\hline X9 & -- & -- & -- & 6,67 & Valid \\
\hline
\end{tabular}

Tabel 3

Uji-T pada Parameter Epsilon ( $(\varepsilon)$

\begin{tabular}{|c|c|c|c|}
\hline Indikator $\mathrm{Y}$ & T-hitung & T-tabel & Keterangan \\
\hline Y1 & 6,04 & 1,9984 & Reliabel \\
\hline Y2 & 6,04 & 1,9984 & Reliabel \\
\hline
\end{tabular}


Tabel 4

Uji-T pada Parameter Delta $(\delta)$

\begin{tabular}{|c|c|c|c|}
\hline Indikator X & T-hitung & T-tabel & Keterangan \\
\hline X1 & 1,79 & 1,9984 & Tidak reliabel \\
\hline X2 & 5,55 & 1,9984 & Reliabel \\
\hline X3 & 0,14 & 1,9984 & Tidak reliabel \\
\hline X4 & 4,33 & 1,9984 & Reliabel \\
\hline X5 & 0,07 & 1,9984 & Tidak reliabel \\
\hline X6 & 5,56 & 1,9984 & Reliabel \\
\hline X7 & 3,42 & 1,9984 & Reliabel \\
\hline X8 & 2,01 & 1,9984 & Reliabel \\
\hline X9 & 5,33 & 1,9984 & Reliabel \\
\hline
\end{tabular}

Tabel 5

Uji-T pada Parameter Gamma $(\gamma)$

\begin{tabular}{|c|c|c|c|c|}
\hline & Pribadi & Referensi & Psikologis & Teknologi \\
\hline Kdebit & 4,76 & 0,17 & 2,34 & 0,55 \\
\hline t-tabel & 1,9984 & 1,9984 & 1,9984 & 1,9984 \\
\hline Keterangan & Kuat & Lemah & Kuat & Lemah \\
\hline
\end{tabular}

\section{b. Pengujian Overall Model}

Overal model adalah model di dalam SEM yang melibatkan model struktural dan model pengukuran yang terintegrasi, jadi merupakan keseluruhan model. Beberapa uji dalam goodness of fit model overall dengan nilainya diberikan pada tabel ini:

Tabel 6 Pengujian Goodness of fit Model Overal pada SEM

\begin{tabular}{|c|c|c|}
\hline Goodness of Fit & Nilai & Keterangan \\
\hline Chi-square & 41.56 & $\geq 0.05$ \\
\hline$\geq 0.05$ & 35 & \\
\hline$\geq 0.05$ & 0.21 & \\
\hline Goodness of Fit Index (GFI) & 0.91 & $\geq 0.90$ \\
\hline Comparative Fit Index (CFI) & 0.96 & $\geq 0.94$ \\
\hline $\begin{array}{c}\text { Root Mean Square Error of } \\
\text { Approximation (RMSEA) }\end{array}$ & 0.051 & $\leq 0.08$ \\
\hline
\end{tabular}

Dari tabel diatas, maka dapat kita simpulkan bahwa model sudah baik. Hal ini dapat kita lihat dari nilai uji goodness of fit yang semuanya memenuhi persyaratan. Hasil analisis ini menunjukkan bahwa: chi square $=41.56$, degree of freedom $=35, p$-value $=0.21$, seluruhnya lebih besar dari 0.05 . Model yang baik biasanya nilai chi square dengan degree of freedom tidak jauh berbeda. Adapun 
hasil dari Goodness of Fit Index (GFI) = 0.91 lebih besar dari 0.90, goodness of fit ini mirip dengan $\mathrm{R}^{2}$ (koefisien determinasi total) pada regresi. Comparative Fit index (CFI) lebih besar dari 0.94 dan Root Mean Square Error of Approximation (RMSEA) $=0.051$ lebih kecil dari 0.08. Secara keseluruhan hasil permodelan ini telah memenuhi kriteria yang dianggap fit dan layak untuk diinterpretasikan.

Jadi model ini telah memenuhi kriteria yang dianggap fit dan layak untuk diinterpretasikan. Adapun tabel 7 berikut merupakan hasil analisis SEM yang dapat digunakan untuk menilai faktor apa yang paling dominan dalam mempengaruhi penggunaan kartu debit.

\section{Tabel.7}

Koefisien Pengaruh Ksi $(\xi)$ pada Eta $(\eta)$

\begin{tabular}{|l|l|l|l|l|}
\hline & Pribadi & Referensi & Psikologis & Teknologi \\
\hline Kdebit & 0,35 & 0,01 & 0,18 & $-0,03$ \\
\hline
\end{tabular}

\section{Interpretasi Model}

Dari hasil uji analisis SEM menunjukkan bahwa faktor pribadi dan faktor psikologis berpengaruh signifikan terhadap perilaku nasabah dalam menggunakan kartu debit. Faktor pribadi indikatornya pendapatan dan pendidikan. Dengan demikian jika pendapatan bertambah maka penggunanaan kartu debit juga bertambah, sebaliknya pada pendidikan hasil analisis SEM menunjukkan nilai signifikan negatif, ini berarti semakin tinggi pendidikan akan mengurangi penggunaan kartu debit.

Sedangkan faktor psikologis terdiri dari promosi dan hadiah, hasil uji ini menunjukkan bahwa semakin sering dilakukan promosi maka penggunaan kartu debit akan bertambah. Demikian pula jika hadiah yang ditawarkan makin banyak dan besar, ini akan menambah penggunaan kartu debit.Dari hasil SEM diatas maka bahwa faktor pribadi dan faktor psikologis mempengaruhi penggunaan kartu debit dapat dibuktikan. Sedangkan hipotesis bahwa faktor referensi dan faktor teknologi mempengaruhi penggunaan kartu debit tidak dapat dibuktikan. Dari 2 faktor yang berpengaruh, maka faktor pribadi memiliki pangaruh yang paling dominan, jadi hipotesis terakhir bahwa ada faktor yang dominan pengaruhnya terhadap penggunaan kartu debit dapat dibuktikan. Dari faktor pribadi ini, pendapatan memiliki pengaruh paling besar, sedangkan faktor psikologis paling besar dipengaruhi oleh promosi 


\section{Implikasi dari Interpretasi Faktor}

Masyarakat Indonesia pada umumnya menyimpan uang di bank hanya untuk menabung saja, sehingga mereka kurang memanfaatkan fasilitas-fasilitas yang diberikan pihak perbankan. Karena itu pihak perbankan harus bisa memasyarakatkan fasilitas kartu debit ini. Batas pemakaian kartu debit yang relatif kecil menyebabkan tidak hanya mereka yang berpendapatan tinggi saja yang bisa memakai kartu debit. Disamping itu prosedur pemakaian kartu debit juga relatif mudah. Hal ini dimaksudkan agar semua nasabah bisa memanfaatkannya. Pihak perbankan harus meningkatkan kerjasama dengan pihak merchant, tidak hanya dikota besar saja, tetapi juga sampai ke kota-kota kecil.

\section{Pembahasan}

Dari hasil penelitian ini secara umum menunjukkan bahwa tidak semua faktor yang diteliti memiliki pengaruh yang signifikan terhadap nasabah dalam menggunakan kartu debit. Dari keempat faktor yang diduga mempunyai pengaruh yang signifikan terhadap nasabah dalam menggunakan kartu debit, hanya faktor pribadi dan faktor psikologis yang berpengaruh signifikan.Faktor pribadi terdiri dari 2 indikator, yaitu pendapatan dan pendidikan yang berpengaruh signifikan terhadap perilaku nasabah dalam menggunakan kartu debit. Dari 2 indikator diatas maka indikator pertama, yaitu pendapatan pengaruhnya terhadap faktor pribadi sangat tinggi dan berpengaruh positif. Ini artinya jika pendapatannya bertambah maka penggunaan kartu debit akan bertambah juga. Hal ini kemungkinan disebabkan karena semakin tinggi pendapatan maka semakin banyak pengeluaran yang dilakukan. Bagi orang yang berpendapatan tinggi, melakukan pembayaran dengan menggunakan kartu debit merupakan sesuatu yang lebih efisien daripada menggunakan uang tunai.

Keuntungan yang diperoleh nasabah dalam menggunakan kartu debit diantaranya,mereka tidak perlu membawa uang dalam jumlah besar. Apalagi sekarang tingkat tindak kejahatan semakin tinggi, resiko sangat besar jika membawa uang tunai dengan jumlah yang besar. Karena itu berbelanja dengan menggunakan kartu debit merupakan cara yang aman. Untuk bisa mencukupi transaksi yang dilakukan, maka nasabah harus menyediakan saldo tabungan 
yang cukup pada rekeningnya. Karena jika nilai saldo yang dimiliki kurang mencukupi untuk pembayaran yang dilakukan maka pihak merchant akan menolak kartu debit tersebut. Karena itu setiap pembayaran dengan menggunakan kartu debit lebih dahulu akan dicek jumlah saldonya.

Adapun faktor referensi kurang berpengaruh signifikan terhadap perilaku nasabah dalam menggunakan kartu debit. Faktor referensi ini terdiri dari dua indikator, yaitu saran keluarga dan saran teman. Kedua indikator ini memiliki pengaruh yang signifikan sebagai variabel indikator dari faktor sosial. Tetapi hasil analisis dari SEM ini menunjukkan bahwa faktor referensi kurang berpengaruh signifikan terhadap perilaku nasabah dalam menggunakan kartu debit. Hal ini kemungkinan disebabkan karena nasabah kurang mendapat referensi atau petunjuk untuk menggunakan kartu debit baik dari keluarga maupun dari teman. Dari hasil kuesioner yang diberikan terhadap responden, kedua indikator ini memang nilai yang diberikan relatif kecil. Hal ini membuktikan bahwa mereka kurang mendapatkan saran untuk menggunakan kartu debit.

Faktor selanjutnya adalah faktor psikologis, faktor ini memiliki pengaruh yang signifikan terhadap perilaku nasabah dalam menggunakan kartu debit. Faktor ini terdiri dari 2 indikator, yaitu promosi dan hadiah. Indikator pertama memiliki pengaruh yang sangat signifikan terhadap variabel yang dibentuk yaitu faktor psikologis. Sedangkan indikator yang kedua juga memiliki nilai yang signifikan tetapi nilainya lebih kecil daripada indikator pertama.

Faktor yang terakhir adalah faktor teknologi. Faktor ini menurut hasil analisis SEM tidak berpengaruh signifikan terhadap perilaku nasabah dalam menggunakan kartu debit. Faktor ini terdiri dari 3 indikator yaitu, transaksi lebih cepat, transaksi lebih aman dan fasilitas on line. Ketiga indikator ini memiliki pengaruh yang signifikan sebagai indikator dari faktor teknologi. Sayangnya dari hasil analisis menunjukkan bahwa faktor ini tidak berpengaruh signifikan terhadap perilaku nasabah dalam menggunakan kartu debit. Padahal transaksi dengan menggunakan kartu debit secara umum lebih cepat daripada menggunakan uang tunai. Dengan pembayaran kartu debit, pendebetan rekening nasabah dan pengkreditan rekening merchant sejumlah nilai transaksi yang dilakukan. Hasil analisis yang menyatakan faktor teknologi tidak signifikan 
pengaruhnya terhadap perilaku nasabah dalam menggunakan kartu debit, mungkin disebabkan kurangnya kemampuan petugas dalam melayani transaksi pembelian barang atau jasa dengan menggunakan kartu debit.

Dari uraian diatas maka dapat kita simpulkan bahwa hipotesis bahwa faktor pribadi dan faktor psikologis mempengaruhi penggunaan kartu debit dapat dibuktikan. Sedangkan hipotesis bahwa faktor referensi dan faktor teknologi mempengaruhi penggunaan kartu debit tidak dapat dibuktikan. Dari 2 faktor yang berpengaruh, maka faktor pribadi memiliki pangaruh yang paling dominan, jadi hipotesis terakhir bahwa ada faktor yang dominan pengaruhnya terhadap penggunaan kartu debit dapat dibuktikan. Dari faktor pribadi ini, pendapatan memiliki pengaruh paling besar, sedangkan faktor psikologis paling besar dipengaruhi oleh promosi.

\section{KESIMPULAN DAN SARAN}

\section{Kesimpulan}

Dari hasil penelitian didapatkan beberapa kesimpulan yang perlu untuk dikemukakan. Terdapat 2 faktor yang dipertimbangkan nasabah dalam menggunakan fasilitas kartu debit. Kedua faktor tersebut berperan dalam mempengaruhi pertimbangan nasabah dalam menggunakan kartu debit. Faktorfaktor tersebut adalah faktor pribadi dan faktor psikologis. Yang termasuk dalam faktor pribadi ini adalah pendapatan dan pendidikan.. Hal ini memberi gambaran bahwa jika pendapatan dan pendidikan nasabah semakin tinggi, maka penggunaan kartu debit yang mereka lakukan juga makin meningkat. Implikasinya bagi pihak perbankan adalah harus mampu memasarkan penggunaan kartu debit bagi semua nasabah. Jadi semua nasabah bisa menggunakan kartu debit. Mungkin pihak perbankan bisa lebih mempermudah operasional penggunaan kartu debit, dan memperluas kerjasama dengan pihak merchant. Tidak hanya di perkotaan saja tetapi juga di desa-desa yang potensial.

Sedangkan faktor psikologis terdiri atas promosi dan hadiah yang ditawarkan. Ini memberi gambaran bahwa semakin sering dan semakin banyak promosi maupun hadiah yang diberikan terhadap nasabah yang menggunakan kartu debit, maka makin bertambah banyak nasabah yang menggunakan kartu 
debit. Peran promosi dalam memasarkan serta mengenalkan jasa dan produk perbankan sangat penting.

Dari dua faktor yang mempengaruhi perilaku nasabah dalam menggunakan kartu debit, faktor pribadi lebih dominan pengaruhnya dalam mempengaruhi nasabah untuk menggunakan kartu debit daripada faktor psikologis.

\section{Saran}

Saran-saran peneliti adalah:

1. Diharapkan pihak bank mampu mengumpulkan informasi eksternal melalui riset, promosi dan cara-cara lain untuk meramalkan bagaimana tanggapan masyarakat dari adanya pemberian fasilitas kartu debit, serta perubahanperubahan yang dinginkan untuk lebih mengembangkan kartu debit.

2. Menciptakan perencanaan dan koordinasi yang berkaitan dengan kecepatan internal seperti pengembangan produk, metode penjualan dan distribusi sehingga dapat memantau ataupun mengikuti perubahan permintaan maupun persaingan dengan produk lain.

3. Lebih memperluas jaringan penggunaan kartu debit dengan jalan memperbanyak kerjasama dengan pihak merchant, baik lokal maupun internasional.

4. Meningkatkan komunikasi dan kemampuan yang dibutuhkan untuk memberikan pemahaman masyarakat terhadap perubahan teknologi agar lebih memahami dalam usaha perubahan sikap dan perilaku dalam perbankan.

5. Agar menjaga kerahasiaan PIN, yang merupakan password untuk dapat menggunakan kartu debit, baik pada teman maupun keluarga. Sebaiknya menggunakan nomor PIN yang acak, yang tidak artinya sehingga orang lain tidak dapat mengira-ngira nomor PIN anda.

\section{DAFTAR PUSTAKA}

Arikunto, Suharsini. 1990. Manajemen Penelitian. Jakarta: PT.Rineka Cipta.

Cooper, Donald R, W Emory 1998. Metode Penelitian Bisnis. Terjemahan, Widyono Soetjipto dan Uka Wikarya. Jakarta: Penerbit Erlangga. 
Dillon, W.R and M. Goldstein, 1984. Multivariate Analysis Methods and Application. New York: John Wiley \& Sons.

Engel, James E, Roger DR, Paul WM. 1994. Perilaku Konsumen. Terjemahan. F.X Budiyanto. Jakarta: Binarupa Aksara.

Tjiptono, Fandy. 2001. Strategi Pemasaran. Yogyakarta: Penerbit Andi Offset.

Hair, Jr, J.F, R.E Anderson, R.L Tatham and W.C Black. 1995. Multivariate Data Analysis with Reading. New York: Prentice Hall.

Johnson, R.A and D.W Wichern. 1982. Applied Multivariate Analysis. New Jersey: Prentice Hall.

Kashmir. 1998. Bank dan Lembaga Keuangan Lainnya. Jakarta: PT. Raja Grafindo Persada.

Kotler, Phillip. 1996. Manajemen Pemasaran. Terjemahan. Hendra Teguh dan Ronny Antonius. Jakarta: PT. Prenhallindo.

Kotler P, Gary Armstrong. 1997. Dasar-Dasar Pemasaran. Terjemahan. Alexander Sindoro. Jakarta: PT. Prenhallindo.

Lukman, Dendawijaya. 2001. Manajemen Perbankan. Jakarta: Penerbit Ghalia Indonesia,

Machdhoero, Mohyi. 1993. Metodologi Penelitian. Malang: UMM Press.

Sharma, S. 1996. Applied Multivariate Techniques. New York: John Wiley \& Sons.

Siamat, Dahlan. 1995. Manajemen Lembaga Keuangan. Jakarta: PT. Intermedia.

Singarimbun, Masri dan Sofian Effendi. 1989. Metode Penelitian Survei. Jakarta: LP3ES.

Sinungan, Muchdarsyah. 1994. Strategi Manajemen Bank. Jakarta: PT. Rineka Cipta.

Solimun. 2002. Structural Equation Modelling (SEM) Lisrel dan AMOS. Malang: Penerbit Universitas Negeri Malang.

Sumarni, Murti. 2002. Manajemen Pemasaran Bank. Yogyakarta: Penerbit Liberty.

Sudjana. 1996. Teknik Analisis Regresi dan Korelasi Bagi Para Peneliti. Bandung: Penerbit Tarsito.

Susilo Sri, Sigit T, Totok Budi S. 2000. Bank Dan Lembaga Keuangan Lainnya. Jakarta: Penerbit Salemba Empat.

Sutrisno. 2001. Analisa Faktor-Faktor yang Mempengaruhi Devident Payout Ratio. TEMA. Volume II, No.1. Maret.

Suyatno, Thomas, Djuhaepah, T. Maralo. 1994. Kelembagaan Perbankan. Jakarta: PT. Gramedia Pustaka Utama.

Swasta, Basu dan Irawan. 1990. Manajemen Pemasaran Modern. Yogyakarta: Penerbit Liberty. 
Walizer, Michael H, Paul L. Wienir. 1986. Metode dan Analisis Penelitian. Terjemahan. Arief Sadiman dan Said Hutagaol. Jakarta: Penerbit Erlangga. 
